\title{
Compressive Radial Neuropathy Developed Under a Fibrotic Band Associated With Rhabdomyolysis and Successfully Treated With Surgery
}

\author{
Ji Yong Kim, MD, Jang-Woo Lee, MD, Sung Oh Cha, MD, Junghyun Park, MD
}

Department of Rehabilitation Medicine, Gangnam Severance Hospital, Yonsei University Medical College, Seoul, Korea

\begin{abstract}
A 34-year-old male patient visited the emergency room with complaint of right wrist drop and foot drop. The day before, he was intoxicated and fell asleep in a room containing barbeque briquettes; After waking up, he noticed that his right wrist and foot were dropped. Upon physical examination, his right wrist extensor, thumb extensor, ankle dorsiflexor, and big toe extensor showed Medical Research Council (MRC) grade 1 power. The initial laboratory tests suggested rhabdomyolysis induced by unrelieved pressure on the right side during sleep. Right foot drop was improved after conservative care and elevated muscle enzyme became normalized with hydration therapy with no resultant acute renal failure. However, the wrist drop did not show improvement and a hard mass was palpated on the follow-up physical examination. Ultrasonography and magnetic resonance imaging studies were conducted and an abnormal mass in the lateral head of the tricep was detected. Axonopathy was suggested by the electrodiagnostic examination. A surgical decompression was done and a fibrotic cord lesion compressing the radial nerve was detected. After adhesiolysis, his wrist extensor power improved to MRC grade 4. Herein, we describe a compressive radial neuropathy associated with rhabdomyolysis successfully treated with surgery and provide a brief review of the related literature.
\end{abstract}

Keywords Radial neuropathy, Rhabdomyolysis, Fibrosis

Received July 2, 2013; Accepted September 2, 2013

Corresponding author: Junghyun Park

Department of Rehabilitation Medicine, Gangnam Severance Hospital, Yonsei University Medical College, 211 Eonju-ro, Gangnam-gu, Seoul 135-720, Korea

Tel: +82-2-2019-3491, Fax: +82-2-3463-7585, E-mail: rmpjh@yuhs.ac

(c) This is an open-access article distributed under the terms of the Creative Commons Attribution Non-Commercial License (http://creativecommons. org/licenses/by-nc/3.0) which permits unrestricted noncommercial use, distribution, and reproduction in any medium, provided the original work is properly cited.

Copyright $\odot 2014$ by Korean Academy of Rehabilitation Medicine

\section{INTRODUCTION}

Radial nerves are vulnerable to external pressure [1], as they run long and winding courses in the upper arm. Compressive radial nerve injury shows good prognosis for spontaneous recovery as time goes by [2].

In such, this paper is a report of a patient with compressive radial neuropathy whose recovery was inhibited by a fibrotic cord induced by the recovery process of the muscle necrosis formed after rhabdomyolysis, and whose symptom was not improved until surgical adhesiolysis. 


\section{CASE REPORT}

A 34-year-old male patient with no significant medical history visited the emergency department with a complaint of right wrist and foot drop. The previous day, he fell asleep while intoxicated in a room with barbeque briquettes. He awoke 10 hours later and noticed his right wrist and foot dropped. He did not remember his sleeping posture that night, but he usually slept on his lateral side.

Several burn blisters were seen on his right arm, knee, leg, and buttock. On the manual muscle test, all four extremities showed Medical Research Council (MRC) grade 5 power, except the right wrist extensor, finger extensor, ankle dorsiflexor, and great toe extensor which all showed MRC grade 1. The patient complained of hypoesthesia of the radial and peroneal nerve distribution on the right side. A blood gas analysis and brain magnetic resonance imaging (MRI) study showed the possibility of carbon monoxide intoxication with high carboxyhemoglobin concentration and focal symmetric ischemic changes in both globus pallidus. However, these did not correlate with his symptoms. Muscle enzyme, including creatine kinase (CK), CK-MB, aspartate aminotransferase (AST), and alanine aminotransferase (ALT) were elevated at 13,245 units/mL, 9.56 units/mL, 169 units/L, and 94

Table 1. Electrodiagnostic study (18 days after onset)

\begin{tabular}{|c|c|c|c|c|}
\hline \multicolumn{2}{|c|}{ Nerve conduction study } & \multirow[t]{2}{*}{ Onset latency (ms) } & \multirow[t]{2}{*}{ Amplitude $^{\text {a) }}$} & \multirow[t]{2}{*}{ Velocity $(\mathrm{m} / \mathrm{s})$} \\
\hline Motor & & & & \\
\hline \multirow[t]{2}{*}{ Rt. median } & Wrist-APB & 3.80 & 13.1 & - \\
\hline & Elbow-Wrist & 8.37 & 12.6 & 52.5 \\
\hline \multirow[t]{2}{*}{ Rt. ulnar } & Wrist-ADM & 2.83 & 12.9 & - \\
\hline & Elbow-Wrist & 7.04 & 12.1 & 57.0 \\
\hline \multirow[t]{3}{*}{ Rt. radial } & Forearm-EIP & NR & NR & - \\
\hline & A.elbow-Forearm & NR & NR & NR \\
\hline & Axilla-A.elbow & NR & NR & NR \\
\hline \multirow[t]{3}{*}{ Lt. radial } & Forearm-EIP & 2.00 & 12.0 & - \\
\hline & A.elbow-Forearm & 3.57 & 11.6 & 99.4 \\
\hline & Axilla-A.elbow & 4.97 & 11.4 & 105 \\
\hline \multirow[t]{2}{*}{ Rt. tibial } & Ankle-AH & 3.22 & 23.4 & - \\
\hline & Knee-Ankle & 10.8 & 18.5 & 51.5 \\
\hline \multirow[t]{2}{*}{ Rt. peroneal } & Ankle-EDB & 4.81 & 0.40 & - \\
\hline & FH-Ankle & 15.2 & 0.13 & 30.8 \\
\hline \multirow[t]{2}{*}{ Lt. peroneal } & Ankle-EDB & 4.25 & 8.9 & - \\
\hline & FH-Ankle & 10.4 & 7.5 & 48.0 \\
\hline \multicolumn{5}{|l|}{ Sensory } \\
\hline Rt. median & Wrist-Finger & 2.94 & 41.4 & - \\
\hline Rt. ulnar & Wrist-Finger & 2.54 & 27.5 & - \\
\hline Rt. superficial radial & Forearm-1st web & 2.27 & 2.8 & - \\
\hline Lt. superficial radial & Forearm-1st web & 2.21 & 47.3 & - \\
\hline Rt. sural & Leg-Ankle & 2.60 & 27.1 & - \\
\hline Rt. superficial peroneal & Calf-Ankle & NR & NR & - \\
\hline Lt. superficial peroneal & Calf-Ankle & 3.04 & 32.1 & - \\
\hline
\end{tabular}

The electrodiagnostic study on the 18th post-injury day was done in the other department. Electromyography couldn't be done due to the patient's refusal at that time.

Rt., right; Lt., left; APB, abductor pollicis brevis; ADM, abductor digiti minimi; EIP, extensor indicis propius; A.elbow, above elbow; NR, no response; AH, abductor hallucis; EDB, extensor digitorum brevis; FH, fibular head.

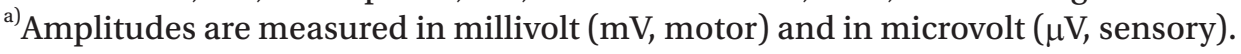


units/L, were found on the initial laboratory tests. The electrocardiography showed nothing abnormal and the myoglobin was measured as $230.4 \mu \mathrm{g} / \mathrm{L}$ in a urine analysis. His urine appeared tea colored at that time. Under massive hydration therapy following the suspicion of rhabdomyolysis, the elevated muscle enzyme and myoglobin became normalized.

Eighteen days after the injury, an electrodiagnostic study was done. The peripheral motor nerve conduction study showed no response of the right radial nerve and low amplitude of the right peroneal nerve; the peripheral sensory nerve conduction study showed low amplitude of the right superficial radial nerve and no response of the right superficial peroneal nerve, suggesting an incomplete lesion on the right radial and peroneal nerve (Table 1). Electromyography was not done at the time due to the patient's refusal.

Conventional physical therapy, including electrical stimulation therapy, was done as treatment for the right wrist and foot drop, with diagnosis of compressive radial and peroneal neuropathy. As time went on, the muscle power of the patient's right ankle dorsiflexor and great toe extensor improved.

The wrist drop didn't show any improvement. A round, hard mass was palpated on the right upper arm in the follow-up physical examination and the electrodiagnostic examination conducted 2 months after the initial event was suggested of the axonopathy of the right radial nerve (Table 2). A mass-like lesion was detected in the ultrasonography so an MRI study was done for further evaluation. The MRI revealed well-defined signal change in the lateral head of the right triceps, with the radial nerve passed around it (Fig. 1). Analysis suggested fibrotic change associated with focal muscle damage with the radial nerve compressed under it; therefore, adhesiolysis surgery was done for radial nerve decompression. A fibrotic cord was detected in the lateral head of the tricep muscle which was compressing the radial nerve; the

Table 2. Electrodiagnostic study (60 days after onset, pre-operation)

\begin{tabular}{|c|c|c|c|c|c|}
\hline & & $\begin{array}{c}\text { Onset latency } \\
(\mathrm{ms})\end{array}$ & Amplitude $^{\text {a) }}$ & $\begin{array}{l}\text { Velocity } \\
(\mathrm{m} / \mathrm{s})\end{array}$ & Finding \\
\hline \multicolumn{6}{|l|}{ Motor } \\
\hline \multirow[t]{2}{*}{ Rt. radial } & Forearm-EIP & NR & NR & - & \\
\hline & A.elbow-Forearm & - & - & NR & \\
\hline \multicolumn{6}{|l|}{ Sensory } \\
\hline Rt. superficial radial & Forearm-1st web & 1.85 & 4.7 & - & \\
\hline \multicolumn{6}{|c|}{ Muscle } \\
\hline $\begin{array}{l}\text { Rt. \& Lt. paraspinalis } \\
\text { (C5-T1) }\end{array}$ & & & & & $\begin{array}{l}\text { No abnormal spontaneous activities } \\
\text { at rest. }\end{array}$ \\
\hline Rt. triceps & & & & & $\begin{array}{l}\text { No abnormal spontaneous activities } \\
\text { at rest. } \\
\text { Normal motor unit action potentials } \\
\text { with full motor unit recruitment } \\
\text { were observed during muscle con- } \\
\text { traction. }\end{array}$ \\
\hline $\begin{array}{l}\text { Rt. EDC } \\
\text { Rt. EIP } \\
\text { Rt. ECRL }\end{array}$ & & & & & $\begin{array}{l}\text { Abnormal spontaneous activities at } \\
\text { rest. } \\
\text { Normal and polyphasic motor unit } \\
\text { action potentials with markedly } \\
\text { reduced motor unit recruitment } \\
\text { were observed during muscle con- } \\
\text { traction. }\end{array}$ \\
\hline
\end{tabular}

Rt., right; Lt., left; EIP, extensor indicis proprius; A.elbow, above elbow; NR, no response; EDC, extensor digitorum communis; ECRL, extensor carpi radialis longus.

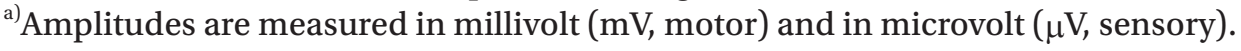



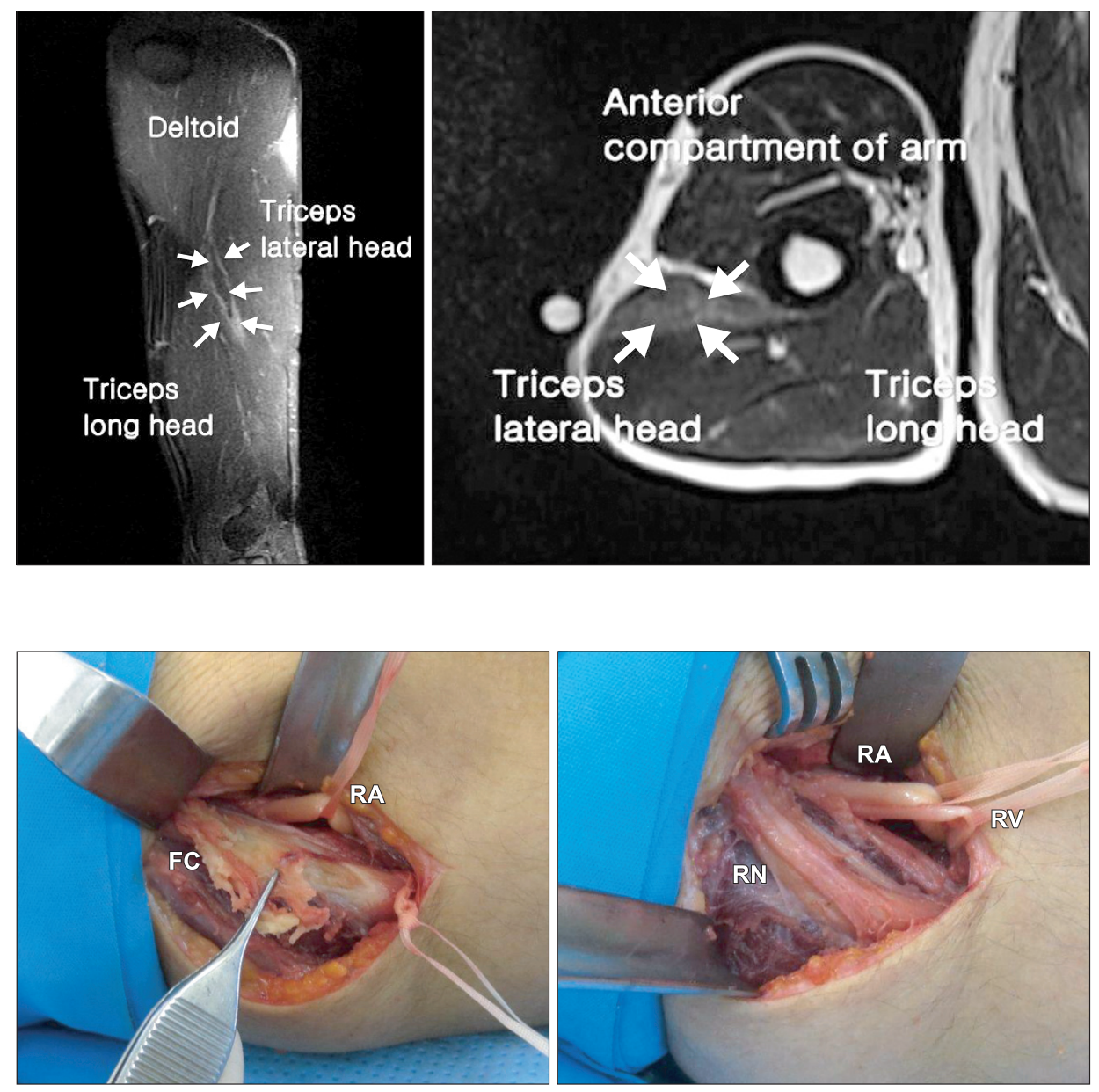

Fig. 1. Right humerus magnetic resonance imaging ( 2 months after onset). A high signal intensity lesion in the lateral head of the tricep muscle with peripheral enhancement pattern in the enhanced image (white arrow).

Fig. 2. Operation findings. (A) A fibrotic cord (FC) is seen. (B) After adhesiolysis, the radial nerve ( $\mathrm{RN})$ become visible. RA, radial artery; $\mathrm{RV}$, radial vein. nerve was confirmed intact after dissection of the deep portion (Fig. 2). Histologic analysis of the surgical specimen revealed focal necrosis and degeneration of muscle fibers with fibrosis. One month after the operation the power of the right wrist and finger extensor has improved to MRC grade 4 and the hypoesthesia presented on the right radial nerve distribution was resolved. Four months after the surgery a peripheral motor nerve conduction study of the right radial nerve and a peripheral sensory nerve conduction study of the right superficial radial nerve showed improvement in the follow-up electrodiagnostic study. The interference patterns of the examined muscles, including the right extensor digitorum communis, the extensor carpi radialis longus, and the extensor indicis proprius, were improved (Table 3 ).

\section{DISCUSSION}

Radial nerve injury is common in the upper arm, particularly where the radial nerve comes into contact with the humerus directly on the proximal humerus and the deltoid tuberosity [1]. With the midshaft fracture, a radial nerve injury can occur around the deltoid tuberosity. The deltoid tuberosity area is also sensitive to external pressure and compressive radial neuropathy called 'Saturday night palsy.' There are a few reports about the prognosis of the compressive radial neuropathy without humerus fracture $[3,4]$ and the largest study among them is Arnold et al. [2]'s study of 91 patients. According to that research, the amplitudes of the radial nerve of sensory nerve action potential and compound motor action potential were within normal limits in the electrodiagnostic study, suggesting focal demyelination was predominant; it supports good prognosis of compressive radial neuropathy as all of the 91 patients fully recovered without sequelae.

Rhabdomyolysis can be a result of drugs and toxins, trauma, muscle ischemia, excessive muscular activity, and prolonged immobilization; several complications can follow, such as compartment syndrome, acute renal failure, and disseminated intravascular coagulation [5]. 
Table 3. Electrodiagnostic study (4 months after operation)

\begin{tabular}{|c|c|c|c|c|c|}
\hline & & $\begin{array}{l}\text { Onset latency } \\
\text { (ms) }\end{array}$ & Amplitude $^{\text {a) }}$ & $\begin{array}{l}\text { Velocity } \\
\text { (m/s) }\end{array}$ & Finding \\
\hline \multicolumn{6}{|l|}{ Motor } \\
\hline \multirow[t]{2}{*}{ Rt. radial } & Forearm-EIP & 1.9 & 1.0 & - & \\
\hline & A.elbow-Forearm & - & - & 27.7 & \\
\hline \multicolumn{6}{|l|}{ Sensory } \\
\hline Rt. superficial radial & Forearm-1st web & 2.35 & 7.7 & - & \\
\hline \multicolumn{6}{|l|}{ Muscle } \\
\hline $\begin{array}{l}\text { Rt. \& Lt. paraspinalis } \\
\text { (C5-T1) }\end{array}$ & & & & & $\begin{array}{l}\text { No abnormal spontaneous activities } \\
\text { at rest. }\end{array}$ \\
\hline Rt. triceps & & & & & $\begin{array}{l}\text { No abnormal spontaneous activities } \\
\text { at rest. } \\
\text { Normal motor unit action potentials } \\
\text { with full motor unit recruitment } \\
\text { were observed during muscle con- } \\
\text { traction. }\end{array}$ \\
\hline $\begin{array}{l}\text { Rt. EDC } \\
\text { Rt. EIP } \\
\text { Rt. ECRL }\end{array}$ & & & & & $\begin{array}{l}\text { Abnormal spontaneous activities at } \\
\text { rest. } \\
\text { Normal and polyphasic motor unit } \\
\text { action potentials and full motor } \\
\text { unit recruitment were observed } \\
\text { during muscle contraction with re- } \\
\text { generation evidence. }\end{array}$ \\
\hline
\end{tabular}

Rt., right; Lt., left; EIP, extensor indicis proprius; A.elbow, above elbow; NR, no response; EDC, extensor digitorum communis; ECRL, extensor carpi radialis longus.

${ }^{\mathrm{a})}$ Amplitudes are measured in millivolt ( $\mathrm{mV}$, motor) and in microvolt $(\mu \mathrm{V}$, sensory).

Alterman et al. [6] reported a case of rhabdomyolysis in which the patient's symptoms developed after a 9-hour urology operation with the patient in the left decubitus position and the subject fully recovered without any complications. The patient in our report received prompt massive hydration therapy upon presentation to the emergency department, with symptoms of rhabdomyolysis and recovered without medical complications of acute renal failure.

In the reported case, the foot drop fully recovered as time went by and it corresponded with the initial diagnosis of simple compressive peroneal neuropathy. About 2 months after the initial event, the power of the patient's right wrist and finger extensor showed no improvement and a palpable hard mass was found during the follow-up physical examination. The electrodiagnostic study done 60 days after the injury presented right radial nerve axonal injury. A fibrotic lesion compressing the radial nerve was revealed upon further evaluation with ultrasonography and MRI. It was found that the recovery of the initial compressed radial nerve neuropathy was inhibited by the fibrotic band constantly pressing on the adjacent radial nerve. Judging from initial inspection in the emergency department of several burn blisters on the patient's right arm and legs, but not on his face, it seemed that he slept with his head on his arms, exerting more pressure on the arm than on the leg. According to the patient's statement and initial laboratory tests which showed elevated muscle enzyme and myoglobin in the urine, it is supposed that he fell asleep in an intoxicated state with his right side in the down position, causing rhabdomyolysis to develop due to unrelieved pressure. Accompanying the rhabdomyolysis, the injured muscle recovered with fibrotic change and the radial nerve was compressed under the fibrotic cord adjacent to the radial nerve. Hwang [7] reported a case of gastrocnemius muscle necrosis and finally fibrosis after radiofrequency-induced tissue coagulation. In that report, a fibrotic change of the necrotic muscle was confirmed by MRI and histologic analysis. We performed a surgical adhesiolysis and found a fibrotic 
cord adhered to the perineural tissue; compression of the radial nerve was visible in the lateral head portion of the tricep muscle.

The fibrotic cord was dissected in the deep layer and the radial nerve was confirmed intact. Prodromo and Goitz [8] reported that surgical management could be helpful in cases of radial nerve injury accompanied with a fractured humerus, but to the best of our knowledge no cases of simple compressive radial nerve injury without humerus fracture treated with surgery have been reported in Korea.

When a patient suspected of compressive radial nerve injury does not gain expected improvement, further evaluation for structural lesion associated with the muscle injury can be helpful to the patient's treatment and recovery.

\section{CONFLICT OF INTEREST}

No potential conflict of interest relevant to this article was reported.

\section{REFERENCES}

1. Wang LH, Weiss MD. Anatomical, clinical, and elec- trodiagnostic features of radial neuropathies. Phys Med Rehabil Clin N Am 2013;24:33-47.

2. Arnold WD, Krishna VR, Freimer M, Kissel JT, Elsheikh B. Prognosis of acute compressive radial neuropathy. Muscle Nerve 2012;45:893-5.

3. Downie AW, Scott TR. An improved technique for radial nerve conduction studies. J Neurol Neurosurg Psychiatry 1967;30:332-6.

4. Escolar DM, Jones HR Jr. Pediatric radial mononeuropathies: a clinical and electromyographic study of sixteen children with review of the literature. Muscle Nerve 1996;19:876-83.

5. Khan FY. Rhabdomyolysis: a review of the literature. Neth J Med 2009;67:272-83.

6. Alterman I, Sidi A, Azamfirei L, Copotoiu S, Ezri T. Rhabdomyolysis: another complication after prolonged surgery. J Clin Anesth 2007;19:64-6.

7. Hwang CH. Excessive gastrocnemius fibrosis developed after radiofrequency-induced cosmetic volume reduction. Aesthetic Plast Surg 2011;35:1172-5.

8. Prodromo J, Goitz RJ. Management of radial nerve palsy associated with humerus fracture. J Hand Surg Am 2013;38:995-8. 